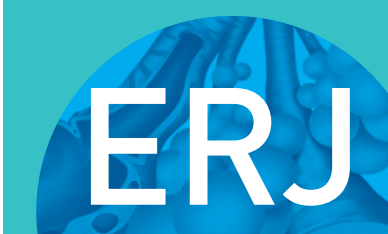

open research
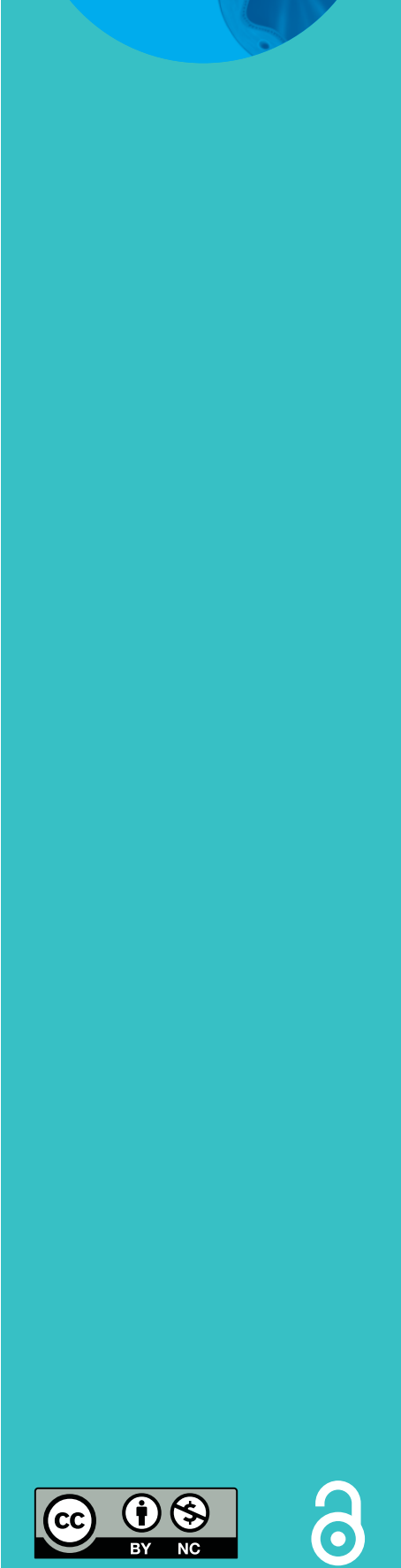

\section{Remission of adult-onset asthma is rare: a 15-year follow-up study}

\author{
Linnéa Almqvist ${ }^{1}$, Eva Rönmark (1) ${ }^{1}$, Caroline Stridsman (10² ${ }^{2}$, Helena Backman (1) ${ }^{1,3}$, \\ Anne Lindberg (10 ${ }^{2}$, Bo Lundbäck (10 ${ }^{4}$ and Linnéa Hedman (10)
}

Affiliations: ${ }^{1}$ Dept of Public Health and Clinical Medicine, Section of Sustainable Health, The OLIN Unit, Umeå University, Umeå, Sweden. ${ }^{2}$ Dept of Public Health and Clinical Medicine, Division of Medicine, The OLIN Unit, Umeå University, Umeå, Sweden. ${ }^{3}$ Dept of Health Sciences, Luleå University of Technology, Luleå, Sweden. ${ }^{4}$ Krefting Research Centre, Institute of Medicine, University of Gothenburg, Gothenborg, Sweden.

Correspondence: Linnéa Hedman, The OLIN studies, Norrbotten County Council, S-971 89 Luleå, Sweden. E-mail: linnea.hedmananorrbotten.se

\section{ABSTRACT}

Background: There are few long-term clinical follow-up studies of adult-onset asthma. The aim of this article was to study clinical characteristics of adult-onset asthma in relation to remission and persistence of the disease in a 15-year follow-up.

Methods: A cohort of 309 adults aged 20-60 years with asthma onset during the last 12 months verified by bronchial variability, was recruited between 1995 and 1999 from the general population in northern Sweden. The cohort was followed-up in $2003(\mathrm{n}=250)$ and between 2012 and $2014(\mathrm{n}=205)$. Structured interviews and spirometry were performed at recruitment and the follow-ups. Bronchial hyperreactivity (BHR) and skin-prick tests were performed at recruitment and blood samples were collected at the last follow-up. Remission of asthma was defined as no asthma symptoms and no use of asthma medication during the last 12 months.

Results: Of eight individuals in remission in 2003, five had relapsed between 2012 and 2014 and in total, $23(11 \%)$ were in remission, while 182 had persistent asthma. Those in remission had higher mean forced expiratory volume in $1 \mathrm{~s} \%$ predicted at recruitment than those with persistent asthma (94.6 versus 88.3, $\mathrm{p}=0.034)$, fewer had severe BHR (27.3\% versus $50.9 \%, \mathrm{p}=0.037)$ and they had less body mass index increase $(+1.6$ versus $+3.0, \mathrm{p}=0.054)$. Of those with persistent asthma, $13 \%$ had uncontrolled asthma and they had higher levels of blood neutrophils than those with partly controlled or controlled asthma.

Conclusion: Higher forced expiratory volume in $1 \mathrm{~s} \%$ predicted and less-severe BHR was associated with remission of adult-onset asthma, but still, the proportion in remission in this 15-year follow-up was low.

@ERSpublications

In this 15-year follow-up of a cohort with adult-onset asthma, the remission rate was low, and predictors of remission were higher $\mathrm{FEV}_{1} \%$ predicted and less-severe bronchial hyperreactivity at asthma onset https://bit.ly/2FEgoFa

Cite this article as: Almqvist L, Rönmark E, Stridsman C, et al. Remission of adult-onset asthma is rare: a 15-year follow-up study. ERJ Open Res 2020; 6: 00620-2020 [https://doi.org/10.1183/ 23120541.00620-2020].

Copyright $\odot$ ERS 2020. This article is open access and distributed under the terms of the Creative Commons Attribution Non-Commercial Licence 4.0. 


\section{Introduction}

Asthma has increased in prevalence worldwide $[1,2]$, which also has been well documented in the Nordic countries since the 1950s [2-6]. Depending on geographical area and different definitions of asthma, the prevalence of asthma among adults varies and has been estimated at about $10 \%$ in western Europe $[1,6,7]$. The epidemiology of asthma also differs by age at onset, for instance with a higher incidence among children and teenagers at around 10 in 1000 per year $[8,9]$, than among adults, at 2-3 in 1000 per year [10-13]. Also remission of asthma is higher among children [8, 14-16], whereas the remission rate among adults is considered to be low, at around $1-2 \%$ per year, when defined as no symptoms common in asthma and no use of asthma medication for at least 1 year $[10,15-19]$. However, the remission rate varies depending on the definition of remission and studies seldom differentiate between asthma with onset in childhood and adulthood.

The few available studies about prognosis of adult-onset asthma indicate that remission is associated with a mild disease, better lung function [18, 20], lower IgE levels [20] and absence of allergic sensitisation [18], whereas a higher degree of bronchial hyperreactivity (BHR) and nasal polyps predicted persistence of the disease [21]. There are also some modifiable factors that may predict the remission of asthma. Substantial weight loss seems to improve asthma control and increase the remission rate $[22,23]$. Studies of the association between smoking and remission show inconclusive results; however, some studies indicate that nonsmoking and smoking cessation favours remission [17, 21, 24]. The knowledge of clinical characteristics of importance for the prognosis of asthma with onset in adulthood is however, limited as there are few long-term clinical follow-up studies.

The aim of this paper was to study clinical characteristics of adult-onset asthma in relation to remission and persistence of the disease in a 15 -year follow-up.

\section{Materials and methods}

\section{Study design and sample}

The study was performed within the research program for Obstructive Lung Disease in Northern Sweden (OLIN). A cohort including 309 individuals aged 20-60 years with onset of asthma within the last 12 months was recruited between 1995 and 1999. The study design and recruitment procedure of the

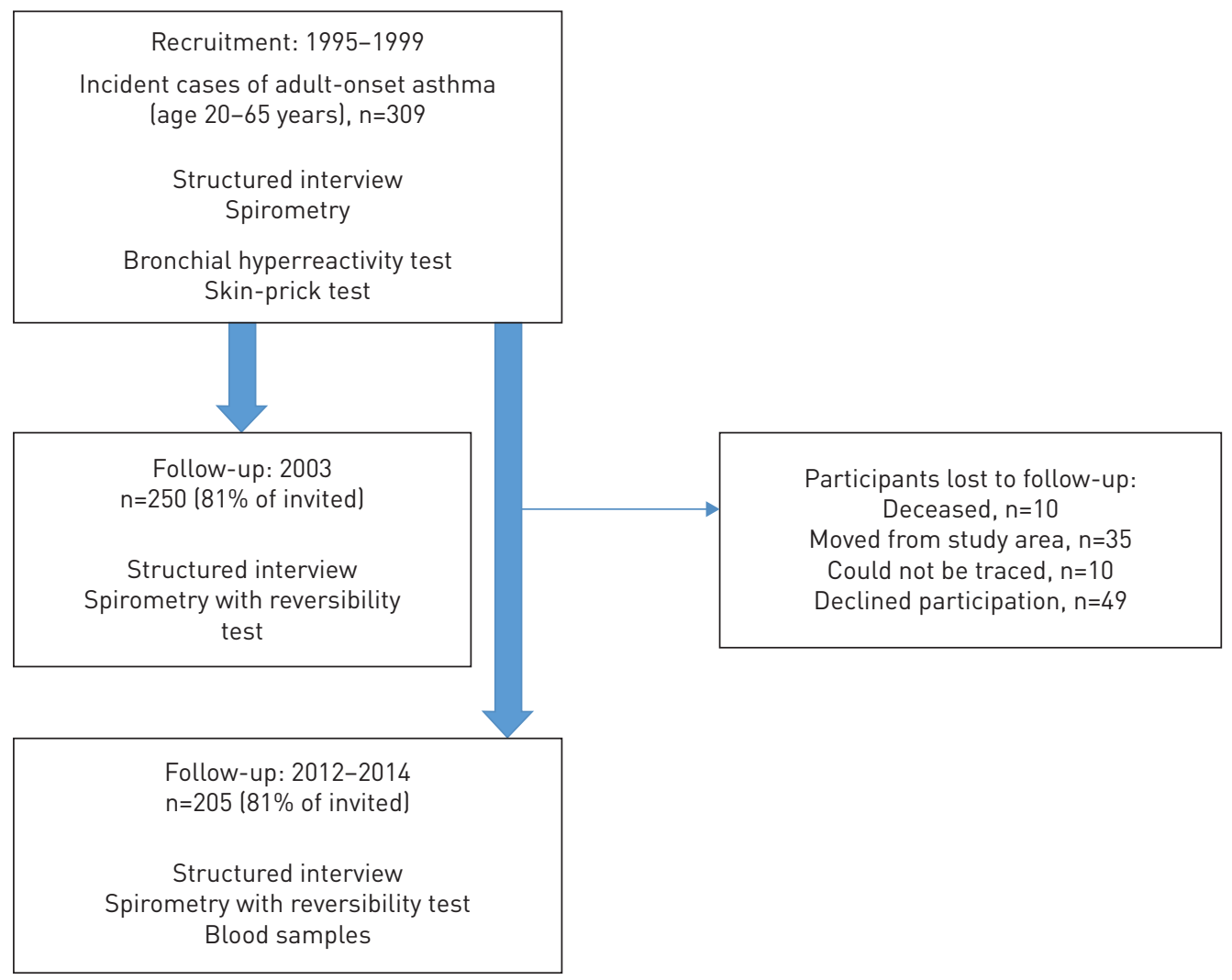

FIGURE 1 Flow chart of the study population. 
participants has previously been described in detail [13]. In short, the strict inclusion criteria included a convincing history of asthma onset within the last 12 months and a physiological test showing bronchial variability was required. Subjects with asthma in childhood and teenage were excluded as well as subjects reporting asthma-like symptoms more than 12 months before recruitment. The cohort has been followed-up twice with clinical examinations: in 2003 [18] and between 2012 and 2014 (figure 1) [25]. The mean follow-up time from asthma onset to the last follow-up was 15.3 years (SD 1.4) and ranged from 12.4 to 18.6 years. The study sample in the current paper is focused on the 205 individuals who participated both at recruitment and the last follow-up. The Regional Ethical Review Board in Umeå, Sweden, approved the studies.

\section{Clinical examinations at recruitment (at asthma onset)}

At recruitment, the subjects participated in a clinical examination, including a structured interview with detailed questions about respiratory symptoms, asthma and comorbid conditions, including rhinitis and eczema. The participants also answered questions about environmental and lifestyle factors, including smoking habits and educational level [13].

Skin-prick tests (SPTs) were carried out for 10 airborne allergens: cat, dog, horse, birch, Timothy grass, mugwort, two mites (Dermatophagoides farinae and Dermatophagoides pteronyssinus) and two moulds (Cladosporium and Alternaria) (Soluprick, ALK, Hørsholm, Denmark). A positive reaction was defined as a mean wheal diameter $\geqslant 3 \mathrm{~mm}$ after $15 \mathrm{~min}$.

Height and weight were measured prior to lung function tests, which were performed following the American Thoracic Society recommendations [26] and using a dry spirometer, the Mijnhardt Vicatest 5. Bronchial variability was verified by bronchial challenge test with methacholine, but if contraindicated, a reversibility test and/or peak flow measurements over 2 weeks was performed [13]. A positive methacholine challenge test was defined as $\mathrm{PC}_{20}$ (provocative concentration causing a $20 \%$ fall in forced expiratory volume in $\left.1 \mathrm{~s}\left(\mathrm{FEV}_{1}\right)\right)<8 \mathrm{mg} \cdot \mathrm{mL}^{-1}$. In the current study, BHR is presented as two cut-offs: $\mathrm{PC}_{20} \leqslant 1 \mathrm{mg} \cdot \mathrm{mL}^{-1}$ (severe) and $\leqslant 2 \mathrm{mg} \cdot \mathrm{mL}^{-1}$ (moderate).

\section{Clinical examinations at follow-up}

The clinical examinations at follow-up between 2012 and 2014 [25] included a similar structured interview as at recruitment with detailed questions about the use of asthma medications. Blood samples were collected for analyses of IgE to airborne allergens, blood neutrophils (B-neu) and blood eosinophils (B-eos). Allergic sensitisation was defined as specific $\mathrm{IgE}>0.35 \mathrm{IU} \cdot \mathrm{mL}^{-1}$, analysed by ImmunoCAP Phadiatop (Thermo Fisher Scientific, Uppsala, Sweden). Among those with a positive Phadiatop, sensitisation to specific allergens were analysed and in the current paper defined as sensitisation to "any pollen" and "any furred animal" as sensitisation to mite and mould are uncommon in this study area [27] Lung function tests were performed using a Jaeger Masterscope spirometer. Reversibility tests were performed after inhalation of $0.4 \mathrm{mg}$ salbutamol. Reversibility was considered significant if $\mathrm{FEV}_{1}$ increased $\geqslant 12 \%$ and $\geqslant 200 \mathrm{~mL}$.

Lung function is presented as pre-bronchodilator $\mathrm{FEV}_{1}$ and forced vital capacity (FVC) values and using the OLIN reference values both at recruitment and follow-up [28].

\section{Definitions}

The definitions used in this study are as follows.

Any respiratory symptom

Any wheeze or attacks of shortness of breath in the last 12 months.

\section{Remission of asthma}

No report of any wheeze or attacks of shortness of breath and no use of asthma medications during the last 12 months.

\section{Body mass index}

Weight $/$ height ${ }^{2}\left(\mathrm{~kg} \cdot \mathrm{m}^{-2}\right)$ and divided into categories according to the World Health Organization: normal $18.5-24.9 \mathrm{~kg} \cdot \mathrm{m}^{-2}$, underweight $<18.5 \mathrm{~kg} \cdot \mathrm{m}^{-2}$, overweight $25-29.9 \mathrm{~kg} \cdot \mathrm{m}^{-2}$ and obese $\geqslant 30$. 


\section{Smoking habits}

Classified as nonsmokers, ex-smokers (stopped $>12$ months prior to examination) and smokers (smoked at least one cigarette-day ${ }^{-1}$ during the last 12 months). Ever-smokers were ex-smokers or current smokers. Pack-years: (number of cigarettes smoked per day/20) xyears.

\section{Atopic comorbidities}

Affirmative answers to the following questions. Hay fever (at recruitment): "Do you have, or have you had hay fever?"; current allergic rhinitis (at follow-up): "Have you had allergic rhinitis in the last 12 months?"; eczema (at recruitment): "Do you have, or have you had eczema?"; current eczema (at follow-up): "Have you had eczema in the last 12 months?"; nasal polyps: "Do you have, or have you had nasal polyps?"; and reflux: "Do you have, or have you had heartburn or acid reflux?"

\section{Occupational exposure to gas, dust or fumes}

Affirmative answer to the question: "Have you been heavily exposed to gas, dust or fumes (GDF) at work?"

\section{Educational level}

Highest educational level achieved: primary school, high school or higher education.

\section{Asthma control}

Among subjects with persistent asthma at follow-up, level of asthma control was classified into controlled, partly controlled and uncontrolled according to Global Initiative for Asthma (GINA) 2006 [29] (table 1).

\section{Treatment at follow-up}

Use of asthma medication during the last 12 months was classified in line with GINA 2017 treatment steps [30]: short-acting $\beta_{2}$-agonists (SABAs) or long-acting $\beta_{2}$-agonists (LABAs) without inhaled corticosteroids (ICSs); SABAs or LABAs with ICSs periodically; low-dose ICSs without LABAs most days per week; combination of low-dose ICSs and LABAs most days per week; or combination of medium-/ high-dose ICSs and LABAs most days per week.

\section{Statistical analyses}

The analyses were carried out using IBM Social Statistical Package for the Social Science, version 24.0 (IBM Corp, New York, USA). Comparisons of proportions were analysed using the Chi-squared test or Fisher's exact test when appropriate. To compare means, independent sample t-test and ANOVA were used. Factors at recruitment associated with remission of asthma at follow-up between 2012 and 2014 were analysed using multivariable logistic regression analysis and expressed as odds ratios with 95\% confidence intervals. A p-value $<0.05$ was considered statistically significant.

\section{TABLE 1 Classification of asthma control according to Global Initiative for Asthma 2006}

$\begin{array}{ccc}\begin{array}{c}\text { Controlled } \\ \text { (all of the below) }\end{array} & \begin{array}{c}\text { Partly controlled } \\ \text { (any of the below) }\end{array} & \text { Uncontrolled } \\ \text { (at least } 3 \text { of the below) }\end{array}$

\section{During the last 4 weeks:}

Asthma symptoms during the day

Limitation of daily activities

Asthma symptoms during the night

Reliever medication

Lung function

During the last 12 months:

Exacerbations ${ }^{\#}$
Twice or less per week

No

No

Used twice or less per week

$\mathrm{FEV}_{1}>80 \%$ predicted

No
Three times or more per week

Yes

Yes

Used three times or more per week

$\mathrm{FEV}_{1}<80 \%$ predicted

At least one
Three times or more per week

Yes

Yes

Used three times or more per week $\mathrm{FEV}_{1}<80 \%$ predicted

At least one

\#: any of the following events in the last 12 months due to asthma: oral corticosteroids and/or antibiotics, emergency healthcare visit with or without hospitalisation, or not being able to work or perform daily activities due to asthma during at least 2 days. FEV ${ }_{1}$ : forced expiratory volume in $1 \mathrm{~s}$. Reproduced from [29] with permission. 


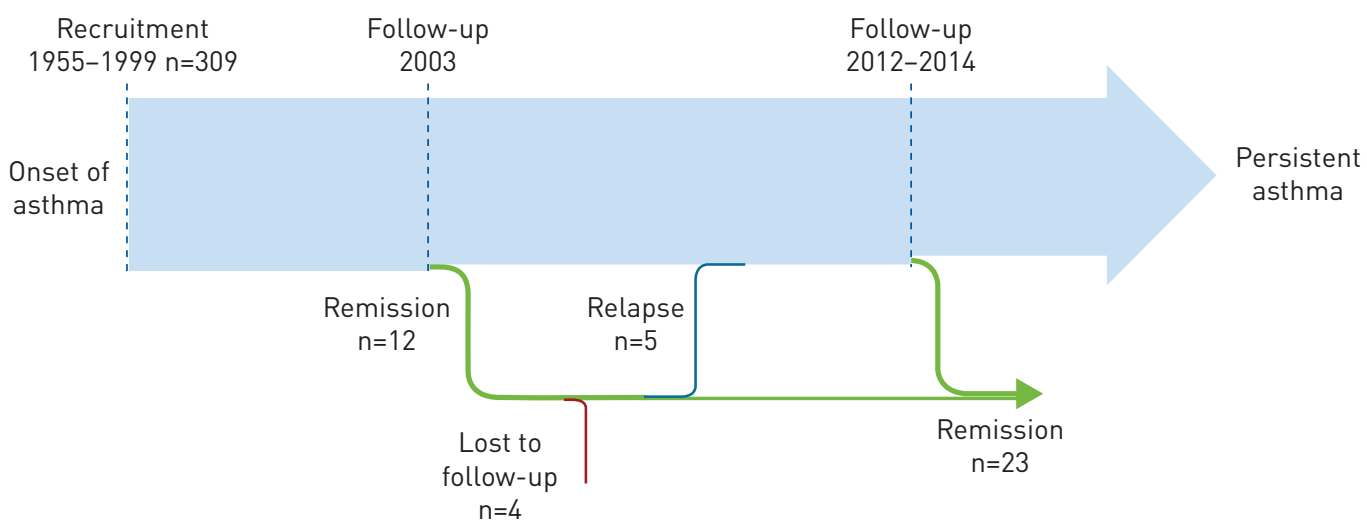

FIGURE 2 Remission and relapse of adult-onset asthma, from recruitment between 1995 and 1999 until follow-up between 2012 and 2014.

\section{Results}

Remission and relapse of asthma

From recruitment until the follow-up in 2003, 12 subjects were in remission [18]. In the 2012-2014 follow-up, eight subjects participated and three were still in remission, whereas five had relapsed (figure 2). Of the three with lasting remission, one was an ex-smoker (pack-years 4.3), two were overweight and none was sensitised. Of the five that relapsed, four had B-neu $>4$, four had controlled asthma and one had

TABLE 2 Basic and clinical characteristics at recruitment between 1995 and 1999, comparing subjects in remission and subjects with persistent asthma at follow-up

\begin{tabular}{|c|c|c|c|c|}
\hline & All & Persistent asthma & Remission & p-value \\
\hline Subjects $\mathrm{n}$ & 205 & 182 & 23 & \\
\hline Female sex & $134(65.4)$ & 121 (66.5) & $13(56.5)$ & 0.344 \\
\hline Age at asthma onset & $39.3 \pm 10.3$ & $39.4 \pm 10.2$ & $38.6 \pm 11.6$ & 0.718 \\
\hline BMI & $25.9 \pm 4.5$ & $25.9 \pm 4.4$ & $26.7 \pm 4.7$ & 0.386 \\
\hline Family history of asthma & $83(40.5)$ & $77(42.3)$ & $6(26.1)$ & 0.135 \\
\hline \multicolumn{5}{|l|}{ BMI classification } \\
\hline Normal weight & 95 (46.3) & $85(46.7)$ & $10(43.5)$ & \\
\hline Overweight & 79 (38.5) & 70 (38.5) & 9 (39.1) & \\
\hline Obesity & $31(15.1)$ & $27(14.8)$ & $4(17.4)$ & $0.717^{+}$ \\
\hline \multicolumn{5}{|l|}{ Smoking habits } \\
\hline Nonsmoker & 105 (51.2) & 95 (52.2) & 10 (43.5) & \\
\hline Ex-smoker & 64 (31.2) & 57 (31.3) & $7(30.4)$ & \\
\hline Current smoker & $36(17.6)$ & $30(16.5)$ & $6(26.1)$ & $0.276^{+}$ \\
\hline Occupational exposure to gas, dust or fumes & 66 (33.3) & $61(34.9)$ & 5 (21.7) & 0.210 \\
\hline \multicolumn{5}{|l|}{ Educational level } \\
\hline Primary school & $21(10.5)$ & 20 (11.3) & $1(4.3)$ & \\
\hline High school & $92(46.0)$ & $81(45.8)$ & $11(47.8)$ & \\
\hline Higher education & $87(43.5)$ & 76 (42.9) & $11(47.8)$ & $0.417^{+}$ \\
\hline \multicolumn{5}{|l|}{ Lung function } \\
\hline $\mathrm{FEV}_{1} \%$ predicted & $89.0 \pm 13.4$ & $88.3 \pm 13.7$ & $94.6 \pm 10.1$ & 0.034 \\
\hline FVC \% predicted & $87.1 \pm 11.6$ & $86.5 \pm 11.7$ & $92.0 \pm 9.5$ & 0.034 \\
\hline \multicolumn{5}{|l|}{ Bronchial hyperreactivity $\mathrm{PC}_{20}{ }^{\#}$} \\
\hline $\mathrm{PC}_{20} \leqslant 1 \mathrm{mg} \cdot \mathrm{mL}^{-1}$ & $89(48.1)$ & $83(50.9)$ & $6(27.3)$ & 0.037 \\
\hline $\mathrm{PC}_{20} \leqslant 2 \mathrm{mg} \cdot \mathrm{mL}^{-1}$ & $120(64.9)$ & 109 (66.9) & $11(50.0)$ & 0.120 \\
\hline \multicolumn{5}{|l|}{ Atopic comorbidities } \\
\hline Hay fever & $82(40.0)$ & $73(40.1)$ & $9(39.1)$ & 0.928 \\
\hline Eczema & 68 (33.2) & $62(34.1)$ & $6(26.1)$ & 0.444 \\
\hline Nasal polyps & $21(10.2)$ & 20 (11.0) & $1(4.3)$ & 0.285 \\
\hline Positive skin-prick test" & $85(42.1)$ & 75 (41.9) & $10(43.5)$ & 0.885 \\
\hline \multicolumn{5}{|c|}{$\begin{array}{l}\text { Data are presented as } \mathrm{n}(\%) \text { or mean } \pm \mathrm{SD} \text {, unless otherwise stated. } \mathrm{BMI} \text { : body mass index; } \mathrm{FEV}_{1} \text { : forced } \\
\text { expiratory volume in } 1 \mathrm{~s} ; \mathrm{FVC} \text { : forced vital capacity; } \mathrm{PC}_{20} \text { : provocative concentration causing a } 20 \% \text { fall in } \\
\mathrm{FEV}_{1} \text {. \#: among the } 185 \text { participating in metacholine challenge test at recruitment; }{ }^{\text {I }} \text { : among the } 202 \\
\text { participating in skin-prick test; }{ }^{+}: \text {analysis performed in a } 3 \times 2 \text { table. Bold values indicate } p<0.05 .\end{array}$} \\
\hline
\end{tabular}


TABLE 3 Changes in BMI, weight and smoking habits from recruitment to follow-up, and lung function, blood neutrophils and eosinophils and allergic sensitisation at follow-up between 2012 and 2014, comparing subjects in remission and subjects with persistent asthma

\section{Persistent asthma}

\section{Subjects $\mathbf{n}$}

Changes in BMI and weight

BMI change

$\%$ weight change

Weight loss

Stable weight

Weight gain

\section{Changes in smoking habits}

Nonsmoker to nonsmoker

Ex-smoker to ex-smoker (mean 11.9 pack-years)

Ex-smoker to smoker

Smoker to smoker (mean 21.1 pack-years)

Smoker to ex-smoker (mean 8.7 pack-years)

Pack-years at follow-up

Lung function at follow-up

$\mathrm{FEV}_{1} \mathrm{pp}$

FVC pp

FEV $_{1}$ reversibility $\geqslant 12 \%$ and $\geqslant 200 \mathrm{~mL}$

Blood neutrophils $10^{9} \cdot \mathrm{L}^{-1}$ at follow-up

$\geqslant 4$

$\geqslant 5$

$\geqslant 6$

mean \pm SD

Blood eosinophils $10^{9} \cdot \mathrm{L}^{-1}$ at follow-up

$\geqslant 0.2$

$\geqslant 0.3$

$\geqslant 0.4$

mean \pm SD

Allergic sensitisation at follow-up

Specific lgE $>0.35 \mathrm{IU} \cdot \mathrm{mL}^{-1}$

Sensitisation to any pollen

Sensitisation to any furry animal
182

Remission

23

$3.0 \pm 3.3$

$10.3 \pm 0.1$

$23(12.6)$

$28(15.4)$

$131(72.0)$

90 (49.5)

57 (31.3)

0

9 (4.9)

$26(14.3)$

$11.4(11.7)$

$89.0 \pm 14.0$

$94.6 \pm 14.2$

$12(7.1)$

$67(39.4)$

$21(12.4)$

9 (5.3)

$3.8 \pm 1.2$

80 (47.1)

$39(22.9)$

23 (13.5)

$0.2 \pm 0.2$

50 (28.4)

37 (21.0)

30 (17.0)
$1.6 \pm 3.3$

$4.9 \pm 0.1$

$6(26.1)$

5 (21.7)

12 (52.2)

10 (43.5)

7 (30.4)

0

4 (17.4)

2 (8.7)

17.7 (12.2)

$0.753^{\S}$

$96.7 \pm 11.8$

0.074

$101.1 \pm 14.5$

1 (4.5)

0.014

$\mathbf{0 . 0 4 3}$

0.547

8 (34.8)

0.669

3 (13.0)

0.570

2 (8.7)

0.386

$4.0 \pm 2.2$

0.406

12 (52.2)

$4(17.4)$

2 (8.7)

$0.2 \pm 0.1$

0.645

0.383

0.399

0.547

5 (21.7)

5 (21.7)

4 (17.4)
0.501

0.937

0.580

Data are presented as $\mathrm{n}(\%)$ or mean $\pm \mathrm{SD}$, unless otherwise stated. $\mathrm{BMI}$ : body mass index; $\mathrm{FEV}_{1}$ : forced expiratory volume in $1 \mathrm{~s}$; FVC: forced vital capacity; Ig: immunoglobulin. " : among the 193 participating in blood sampling for cell count at follow-up; ": among the 199 participating in blood samples for IgE at follow-up; ${ }^{+}$: analysis performed in a $3 \times 2$ table; ${ }^{\S}$ : analysis performed in a $5 \times 2$ table. Bold values indicate $p<0.05$.

uncontrolled asthma at follow-up. Of the 205 individuals in the follow-up between 2012 and 2014, 23 (11.2\%), fulfilled the criteria for remission, yielding a remission rate between recruitment and the last follow-up of $<1 \%$ per year.

\section{Characteristics at recruitment in relation to remission of asthma between 2012 and 2014}

Subjects in remission had higher mean $\mathrm{FEV}_{1} \%$ predicted (\% pred) than those with persistent asthma, both at recruitment ( $94.6 \%$ versus $88.3 \%, \mathrm{p}=0.034$, table 2 ) and at follow-up ( $96.7 \%$ versus $89.0 \%, \mathrm{p}=0.014$, table 3). Also, FVC \% pred was significantly higher among those in remission. Severe BHR at recruitment was more common among those with persistent asthma than those in remission ( $50.9 \%$ versus $27.3 \%$, $\mathrm{p}=0.037$, table 2). The association between remission and $\mathrm{FEV}_{1} \%$ pred and severe $\mathrm{BHR}$ at recruitment remained significant also after adjustment for sex, age, family history of asthma, body mass index (BMI) and smoking habits at recruitment (figure 3). There were no differences between subjects in remission and those with persistent asthma regarding sex, age at asthma onset, family history of asthma, BMI categories, smoking habits, educational level, occupational exposure to GDF, comorbidities or positive SPT at recruitment.

\section{Remission of asthma in relation to changes in weight, BMI and smoking habits from asthma} onset to follow-up between 2012 and 2014

Subjects with persistent asthma tended to have a greater BMI increase (3.0 versus 1.6, $\mathrm{p}=0.054$ ) and mean per cent weight gain $(10.3 \%$ versus $4.9 \%, \mathrm{p}=0.059)$ than those in remission. Among those in remission, 
OR

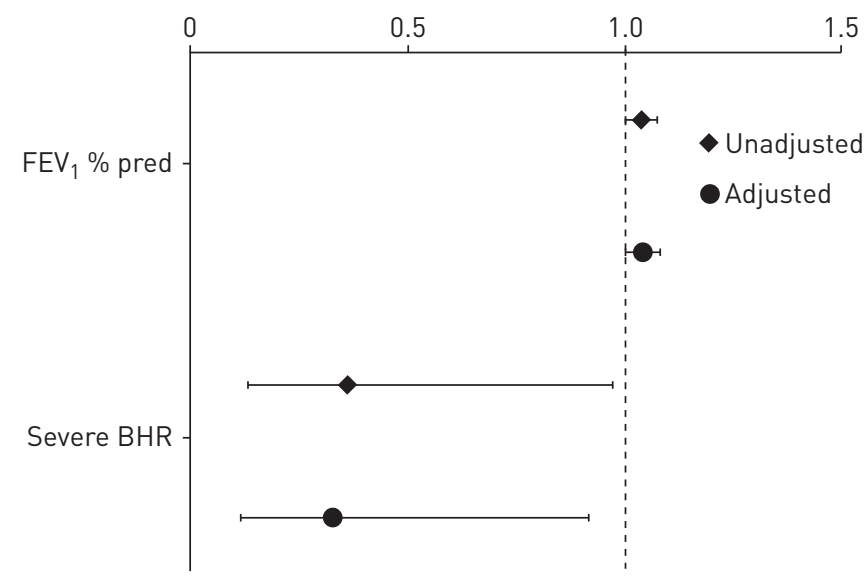

FIGURE 3 Remission of adult-onset asthma at follow-up between 2012 and 2014 in relation to forced expiratory volume in $1 \mathrm{~s}\left(\mathrm{FEV}_{1}\right) \%$ predicted and severe bronchial hyperreactivity $\left(\mathrm{BHR} \mathrm{PC}_{20} \leqslant 1 \mathrm{mg} \cdot \mathrm{mL}^{-1}\right)$ at recruitment between 1995 and 1999. Logistic regression analyses, presented as unadjusted and adjusted for sex, age, family history of asthma, body mass index and smoking habits at recruitment. $\mathrm{PC}_{20}$ : provocative concentration causing a $20 \%$ fall in $\mathrm{FEV}_{1}$.

26.1\% had lost weight compared to $12.6 \%$ among those with persistent asthma, $\mathrm{p}=0.118$ (table 3 ). Changes in smoking habits were not associated with remission.

\section{Clinical characteristics of subjects with persistent asthma by level of asthma control}

Of the 182 individuals (88.8\%) with persistent asthma at follow-up, 55\% had controlled, 32\% had partly controlled and $13 \%$ had uncontrolled asthma. At follow-up, the mean $\mathrm{FEV}_{1} \%$ pred was significantly higher among those with controlled asthma (91.9\%) than those with partly controlled (85.0\%) or uncontrolled asthma (86.6\%) (table 4). The proportion of subjects having B-neu $\geqslant 4.0 \times 10^{9} \cdot \mathrm{L}^{-1}$ was significantly higher among those with uncontrolled asthma (65.2\%) than partly controlled (32.1\%) or controlled asthma (37.4\%). Also, the mean B-neu level was significantly higher among those with uncontrolled asthma, whereas the mean levels of B-eos were similar. Levels of asthma control were not related to sex, age at asthma onset, age at follow-up, mean BMI, BMI categories, smoking habits, occupational exposure to GDF, reversibility, allergic sensitisation (table 4) or change in weight or BMI (data not shown).

All subjects with uncontrolled asthma reported "any respiratory symptom" during the last 12 months, compared to $89.7 \%$ of those with partly controlled asthma, and $88.0 \%$ of those with controlled asthma (table 5). The majority of those with uncontrolled asthma used medium- or high-dose ICSs with LABAs most days per week (58.3\%), compared with $34.5 \%$ of partly controlled and $23.0 \%$ of controlled asthma $(\mathrm{p}=0.004)$.

\section{Lost to follow-up}

Of the original cohort of 309 subjects, 10 individuals had died, 35 had moved from the county, 10 could not be traced, and 49 of those possible to invite declined participation (figure 1). The nonparticipants $(\mathrm{n}=49)$ were significantly younger than the 205 participants (mean age 32.1 versus 39.3 years, $\mathrm{p}<0.001$ ), but there were no significant differences regarding respiratory symptoms, positive SPT, weight, BMI, smoking habits or $\mathrm{FEV}_{1} \%$ pred at recruitment.

\section{Discussion}

This population-based study included a 15-year follow-up of a cohort with clinically verified adult-onset asthma. The remission rate was low and at follow-up the vast majority had persistent asthma. Lower FEV 1 $\mathrm{pp}$ and severe bronchial hyperreactivity at asthma onset was associated with persistent asthma. Almost every other individual with persistent asthma had uncontrolled or partly controlled disease at follow-up.

Our study is one of the few available long-term follow-up studies of adult-onset asthma where strict inclusion criteria have been used; besides verification of bronchial variability the presence of several symptom variables was also required [13]. In a previous 5-year follow-up of our cohort, the remission rate was low at 0.8 in 100 per year [18] and similar to the current follow-up. However, of those in remission, five of eight had relapsed until the current follow-up. What may seem as remission in a short-term 
TABLE 4 Characteristics of subjects with persistent asthma at follow-up, by asthma control classified according to Global Initiative for Asthma 2006 [29] criteria

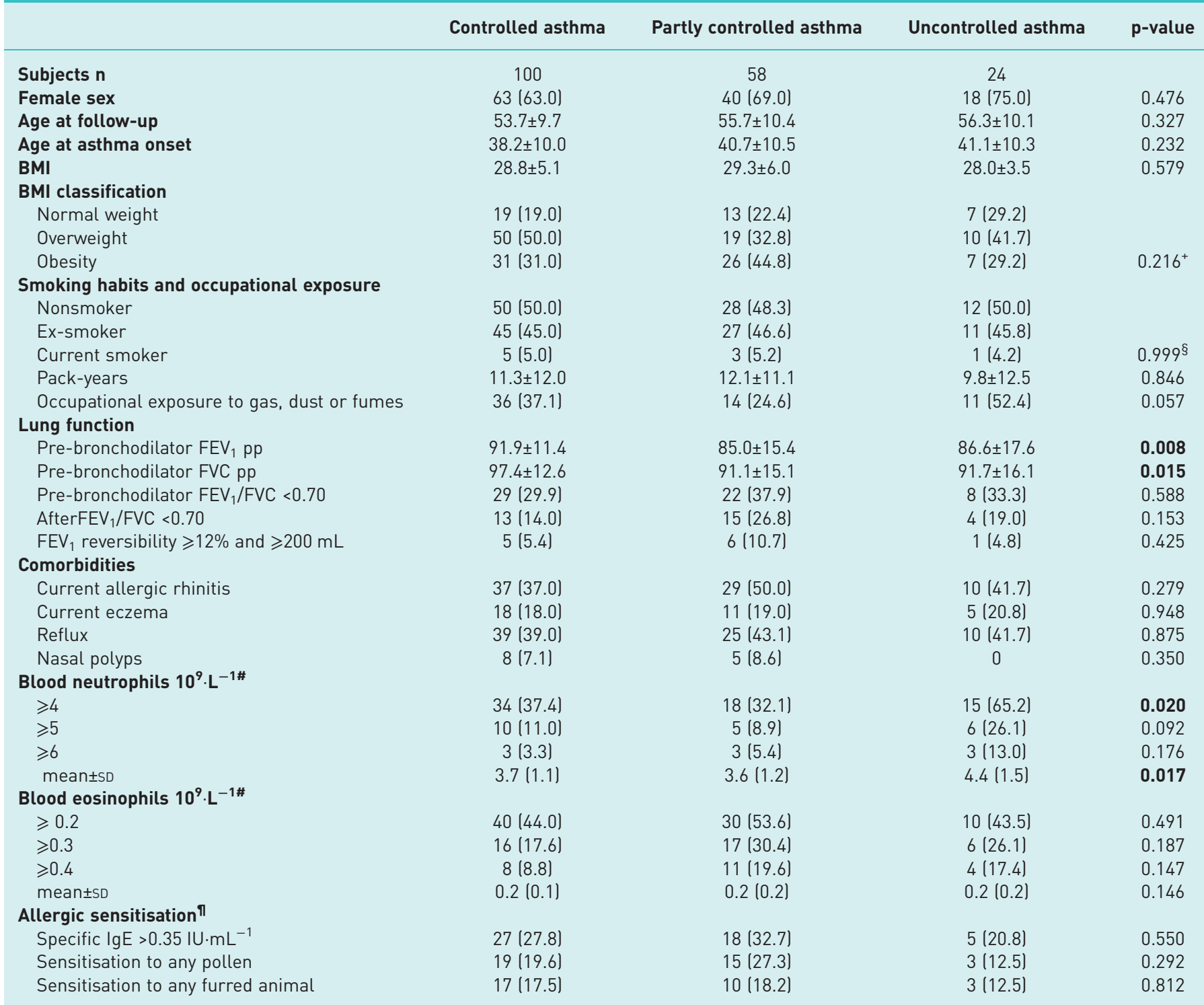

Data are presented as $\mathrm{n}(\%)$ or mean $\pm \mathrm{SD}$, unless otherwise stated. $\mathrm{BMI}$ : body mass index; $\mathrm{FEV}_{1}$ : forced expiratory volume in $1 \mathrm{~s}$; FVC: forced vital capacity; Ig: immunoglobulin. " : among the 170 participating in blood sampling for cell count; ": among the 176 participating in blood sampling for $\lg \mathrm{E}_{;}{ }^{+}$: analysis performed in a $3 \times 3$ table. Bold values indicate $p<0.05$.

follow-up, could in fact only be a temporary period with absence of symptoms, particularly among those with mild intermittent asthma $[18,20]$. Thus, low remission rate of adult-onset asthma is supported by the current study. Both in the current follow-up, as well as in the 5-year follow-up [18] of our cohort, higher $\mathrm{FEV}_{1} \mathrm{pp}$ predicted remission of adult-onset asthma. Furthermore, in this last follow-up we also found that severe BHR counteracted remission. This is in line with a similar study of 170 individuals with adult-onset asthma followed for 5 years [21]. Thus, measures to maintain good lung function and suppress hyperreactivity may increase the probability of remission.

The majority of our participants had gained weight, similar to an increase of obesity observed in the general population in high-income countries over the last decades. It has been shown that weight loss improves lung function [31], asthma control and quality of life among obese people with asthma [32, 33] and that weight loss can lead to decreased airway hyperreactivity [22, 34]. In the Finnish Seinäjoki Adult Asthma Study (SAAS), high baseline BMI was a predictor for uncontrolled asthma at a follow-up after 12 years [20]. In our study we found a trend that a greater weight gain was associated with persistent 
TABLE 5 Any respiratory symptoms and use of asthma medication classified according to asthma treatment among subjects with persistent asthma, by asthma control classified according to Global Initiative for Asthma 2006 criteria [29] at follow-up

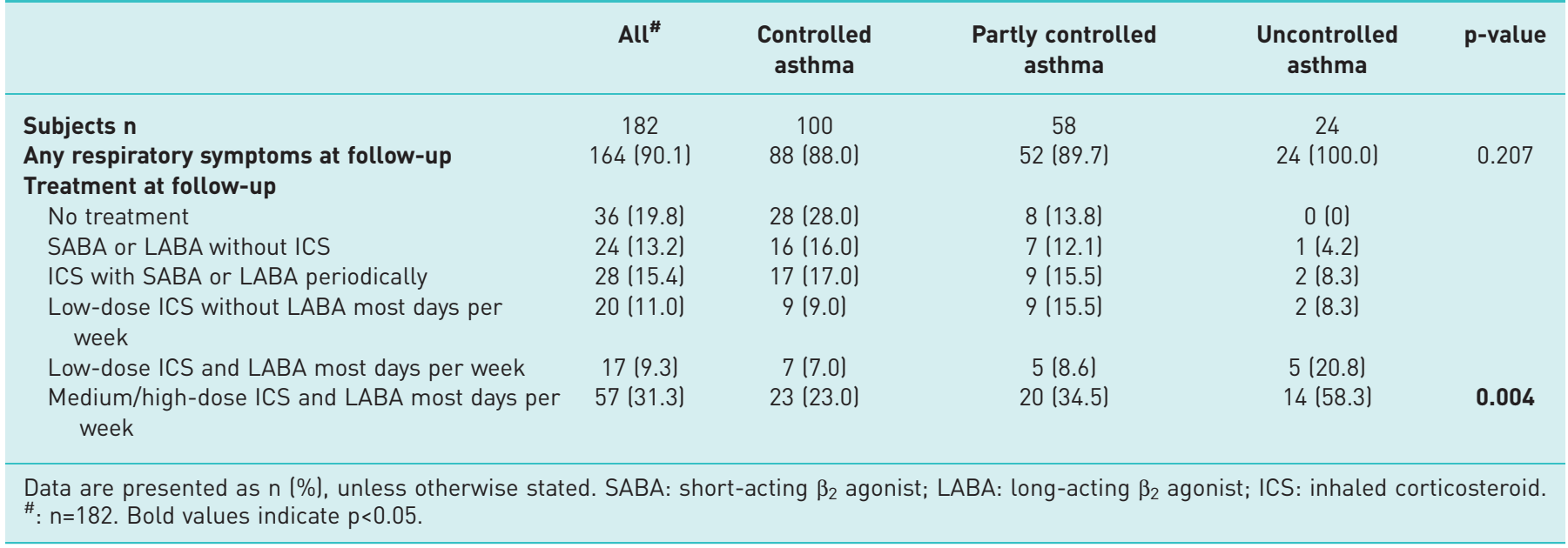

asthma but not with level of asthma control. Due to the few subjects in remission, as well as few subjects losing weight, our study lacks power to fully analyse the effect of weight loss on remission of asthma.

There is no gold standard to define remission of asthma, which is why comparisons between studies must be made cautiously. Remission of asthma from childhood to adulthood has been reported to be high at $10-65 \%[14-16,35,36]$. The remission rate in our cohort of adult-onset asthma was $11 \%$ during the 15-year follow-up. Among the few other prospective studies of adult-onset asthma, higher remission rates have been shown, 16\% during 5 years [21] and 20\% during 10 years [24], while the previously discussed Finnish SAAS showed a lower rate of $3 \%$ during 12 years [20]. However, these studies have a different methodology and definitions. For instance, we defined adult-onset asthma based on strict inclusion criteria regarding age at onset, after 20 years of age and also required a clinically verified bronchial variability, whereas others have used 15 years as the age limit for adult onset [20] or used postal questionnaire reports to define adult-onset asthma [24]. An initial interest at the recruitment of the cohort was to study the importance of occupational exposure, therefore we used 20 years as threshold for adult asthma onset. However, as we used strict inclusion criteria, some individuals with mild asthma may have been excluded at recruitment, and as mild asthma is associated with remission, the remission rate may have been somewhat underestimated. However, taken together, the remission rate of adult-onset asthma is low and considerably lower than remission of asthma in children.

In our study, there was no significant association between current smoking and neither remission nor asthma control. Contrary to our expectations, we found that those in remission tended to have more pack-years than those with persistent asthma. This may be explained by a "healthy smoker effect" (i.e. individuals with fewer respiratory symptoms are more prone to continue smoking). However, the associations between sex, smoking and obesity in relation to asthma are difficult to disentangle. For instance, in a cross-sectional study, the association between smoking and asthma was stronger in overweight women than overweight men [37]. Further, current smoking may reduce weight gain, whereas smoking cessation increases weight gain [38]. Thus, smokers may hesitate to quit due to fear of gaining weight, which should be taken into account in smoking cessation support.

Of those with persistent asthma, subjects with uncontrolled asthma had higher B-neu levels than subjects with controlled asthma. Close to $60 \%$, of those with uncontrolled asthma used medium/high doses of ICSs most days per week, corresponding to GINA treatment step 4. It is known that neutrophilic inflammation is associated with poor response to glucocorticoid steroids [39] and it has even been suggested that glucocorticoid steroid treatment may increase the level of sputum neutrophilia [39]. It has also been suggested that obesity in asthma could be associated with more neutrophilic inflammation [32, 40], especially among women [40]. However, in the current study there were no significant associations between overweight and asthma control but a slightly higher proportion of those with uncontrolled asthma had occupational exposure to GDF, which also could contribute to neutrophilic inflammation. On the other hand, one-quarter of those with partly controlled asthma had no treatment or merely had SABAs or LABAs without ICSs and almost $40 \%$ of those with uncontrolled asthma had low-dose ICSs with or without LABAs. Thus, these individuals would benefit from optimisation of pharmaceutical treatment but also lifestyle factors and environmental exposures. 
The strengths of the current study are the strict criteria for the diagnosis of adult-onset asthma and the longitudinal study design with a long follow-up time. The validity of the study is strengthened by the high participation rate at both recruitment [13] and follow-up [18]. Even though there was a loss to follow-up, comparison of participants and nonparticipants indicated no major selection bias, thus we consider that the study population is representative of the cohort. The limited number of cases in remission did, however, not allow subgroup analyses. There was a decrease in the prevalence of allergic sensitisation from recruitment to follow-up that in part, could be explained by the use of different measuring methods of SPT and IgE levels. On the other hand, remission of allergic sensitisation to airborne allergens is common among adults [27]. Unfortunately, we lack information on IgE levels as well as B-eos and B-neu levels at recruitment. Further, another limitation is that BHR tests were not performed at follow-up. Although we lack information about the prescribed doses of asthma medication, we have detailed information about what the participants in reality are using.

In conclusion, even though better lung function and less-severe BHR was associated with remission, and those in remission tended to have less weight gain, the proportion in remission was low in this long-term cohort study of adult-onset asthma. Thus, with few exceptions, adult-onset asthma can be considered a persistent disease. Moreover, a high proportion of those with persistent asthma did not have well-controlled disease and would certainly benefit from optimised treatment.

Acknowledgements: Ann-Christin Jonsson, Britt-Marie Eklund and Karin Östling (The OLIN Studies, Norrboten County Council, Sweden) are acknowledged for data collection.

Conflict of interest: L. Almqvist has nothing to disclose. E. Rönmark has nothing to disclose. C. Stridsman has nothing to disclose. H. Backman reports speaking fees from Boehringer Ingelheim and AstraZeneca outside the submitted work. A. Lindberg reports personal fees for lectures and an advisory board from Boehringer Ingelheim, personal fees for an advisory board from AstraZeneca, personal fees for lectures from Novartis, and personal fees for an advisory board from GlaxoSmithKline, outside the submitted work. B. Lundbäck reports personal fees for participating at advisory board meetings from GSK and Sanofi, outside the submitted work. L. Hedman has nothing to disclose.

Support statement: Financial support was received from the Swedish Heart Lung Foundation (ALF), a regional agreement between Umeå University and Västerbotten County Council, the Swedish Council for Working Life (RALF), Center for Environmental Research, Umeå (CMF), the Swedish Asthma-Allergy Foundation, the Swedish Foundation for Health Care Science and Allergy Research (Vårdal), Norrbotten County Council and Visare Norr. Additional support was provided by GlaxoSmithKline and Thermo Fisher Scientific. Funding information for this article has been deposited with the Crossref Funder Registry.

\section{References}

1 Adult asthma. In: Gibson GJ, Loddenkemper R, Sibille Y, et al eds. The European Lung White Book. Sheffield, European Respiratory Society, 2013; pp. 138-147.

2 Lundbäck B, Backman H, Lötvall J, et al. Is asthma prevalence still increasing? Expert Rev Respir Med 2016; 10: 39-51.

3 Brogger J, Bakke P, Eide GE, et al. Long-term changes in adult asthma prevalence. Eur Respir J 2003; 21: 468-472.

4 Browatzki A, Ulrik CS, Lange P. Prevalence and severity of self-reported asthma in young adults, 1976-2004. Eur Respir J 2009; 34: 1046-1051.

5 Kainu A, Pallasaho P, Piirila P, et al. Increase in prevalence of physician-diagnosed asthma in Helsinki during the Finnish Asthma Programme: improved recognition of asthma in primary care? A cross-sectional cohort study. Prim Care Respir J 2013; 22: 64-71.

6 Backman H, Räisänen P, Hedman L, et al. Increased prevalence of allergic asthma from 1996 to 2006 and further to 2016-results from three population surveys. Clin Exp Allergy 2017; 47: 1426-1435.

7 Borna E, Nwaru BI, Bjerg A, et al. Changes in the prevalence of asthma and respiratory symptoms in western Sweden between 2008 and 2016. Allergy 2019; 74: 1703-1715.

8 Rönmark E, Jönsson E, Platts-Mills T, et al. Incidence and remission of asthma in schoolchildren: report from the obstructive lung disease in northern Sweden studies. Pediatrics 2001; 107: E37.

9 Hedman L, Bjerg A, Lundbäck B, et al. Conventional epidemiology underestimates the incidence of asthma and wheeze-a longitudinal population-based study among teenagers. Clin Transl Allergy 2012; 2: 1.

10 Ekerljung L, Rönmark E, Larsson K, et al. No further increase of incidence of asthma: incidence, remission and relapse of adult asthma in Sweden. Respir Med 2008; 102: 1730-1736.

11 Eagan TML, Bakke PS, Eide GE, et al. Incidence of asthma and respiratory symptoms by sex, age and smoking in a community study. Eur Respir J 2002; 19: 599-605.

12 Pallasaho P, Juusela M, Lindqvist A, et al. Allergic rhinoconjunctivitis doubles the risk for incident asthma-results from a population study in Helsinki, Finland. Respir Med 2011; 105: 1449-1456.

13 Rönmark E, Andersson C, Nyström L, et al. Obesity increases the risk of incident asthma among adults. Eur Respir J 2005; 25: 282-288.

14 Andersson M, Hedman L, Bjerg A, et al. Remission and persistence of asthma followed from 7 to 19 years of age. Pediatrics 2013; 132: 435.

15 Strachan DP, Butland BK, Anderson HR. Incidence and prognosis of asthma and wheezing illness from early childhood to age 33 in a national British cohort. BMJ 1996; 312: 1195-1199.

16 Sears MR, Greene JM, Willan AR, et al. A longitudinal, population-based, cohort study of childhood asthma followed to adulthood. $N$ Engl J Med 2003; 349: 1414-1422. 
17 Rönmark E, Jönsson E, Lundbäck B. Remission of asthma in the middle aged and elderly: report from the Obstructive Lung Disease in Northern Sweden study. Thorax 1999; 54: 611-613.

18 Rönmark E, Lindberg A, Watson L, et al. Outcome and severity of adult onset asthma: report from the obstructive lung disease in northern Sweden studies (OLIN). Respir Med 2007; 101: 2370-2377.

19 Panhuysen CI, Vonk JM, Koëter GH, et al. Adult patients may outgrow their asthma: a 25-year follow-up study. Am J Respir Crit Care Med 1997; 155: 1267-1272.

20 Tuomisto LE, Ilmarinen P, Niemelä O, et al. A 12-year prognosis of adult-onset asthma: Seinäjoki Adult Asthma Study. Respir Med 2016; 117: 223-229.

21 Westerhof GA, Coumou $\mathrm{H}$, de Nijs SB, et al. Clinical predictors of remission and persistence of adult-onset asthma. J Allergy Clin Immunol 2018; 141: 104-109. e3.

22 Dixon AE, Pratley RE, Forgione PM, et al. Effects of obesity and bariatric surgery on airway hyperresponsiveness, asthma control, and inflammation. J Allergy Clin Immunol 2011; 128: 50-52.

23 Juel CT-B, Ali Z, Nilas L, et al. Asthma and obesity: does weight loss improve asthma control? a systematic review. J Asthma Allergy 2012; 5: 21-26.

24 Holm M, Omenaas E, Gíslason T, et al. Remission of asthma: a prospective longitudinal study from northern Europe (RHINE study). Eur Respir J 2007; 30: 62-65.

25 Backman H, Hedman L, Stridsman C, et al. A population-based cohort of adults with asthma: mortality and participation in a long-term follow-up. Eur Clin Respir J 2017; 4: 1334508.

26 ATS statement: Snowbird workshop on standardization of spirometry. Am Rev Respir Dis 1979; 119: 831-838.

27 Warm K, Backman $\mathrm{H}$, Lindberg A, et al. Low incidence and high remission of allergic sensitization among adults. J Allergy Clin Immunol 2012; 129: 136-142.

28 Backman H, Lindberg A, Odén A, et al. Reference values for spirometry: report from the Obstructive Lung Disease in Northern Sweden studies. Eur Clin Respir J 2015; 2: 26375.

29 Global Initiative for Asthma. Global Strategy for Asthma Management and Prevention. 2006.

30 Global Initiative for Asthma. Global Strategy for Asthma Management and Prevention. 2017.

31 Hakala K, Stenius-Aarniala B, Sovijärvi A. Effects of weight loss on peak flow variability, airways obstruction, and lung volumes in obese patients with asthma. Chest 2000; 118: 1315-1321.

32 van Huisstede A, Rudolphus A, Cabezas MC, et al. Effect of bariatric surgery on asthma control, lung function and bronchial and systemic inflammation in morbidly obese subjects with asthma. Thorax 2015; 70: 659-667.

33 Vortmann M, Eisner MD. BMI and health status among adults with asthma. Obesity 2008; 16: 146-152.

34 Sideleva O, Black K, Dixon AE. Effects of obesity and weight loss on airway physiology and inflammation in asthma. Pulm Pharmacol Ther 2013; 26: 455-458.

35 Burgess JA, Matheson MC, Gurrin LC, et al. Factors influencing asthma remission: a longitudinal study from childhood to middle age. Thorax 2011; 66: 508-513.

36 Fuchs O, Bahmer T, Rabe KF, et al. Asthma transition from childhood into adulthood. Lancet Respir Med 2017; 5: 224-234.

37 Chen Y, Mai X-M. Smoking and asthma in men and women with normal weight, overweight, and obesity. J Asthma 2011; 48: 490-494.

38 Tian J, Venn A, Otahal P, et al. The association between quitting smoking and weight gain: a systematic review and meta-analysis of prospective cohort studies. Obes Rev 2015; 16: 883-901.

39 Green RH, Brightling CE, Woltmann G, et al. Analysis of induced sputum in adults with asthma: identification of subgroup with isolated sputum neutrophilia and poor response to inhaled corticosteroids. Thorax 2002; 57: 875-879.

40 Scott HA, Gibson PG, Garg ML, et al. Airway inflammation is augmented by obesity and fatty acids in asthma Eur Respir J 2011; 38: 594-602. 